\title{
EMBEBIÇÃO E PROFUNDIDADE DE SEMEADURA DE SEMENTES NÃO REVESTIDAS E REVESTIDAS DE FORRAGEIRAS
}

Luciana de Oliveira Derré ${ }^{1}$, Fabiana Lima Abrantes ${ }^{2}$, Elton Anderson Aranda ${ }^{2}$, Eduardo Mazetti Feitosa ${ }^{2}$, Ceci Castilho Custódio ${ }^{2}$

${ }^{1}$ Faculdade Centro Matogrossense - FACEM, Sorriso, MT. ${ }^{2}$ Universidade do Oeste Paulista - UNOESTE, Agronomia, Presidente Prudente, SP

\section{RESUMO}

O objetivo deste trabalho foi avaliar os efeitos do revestimento de sementes durante a embebição e na emergência e crescimento inicial de seis gramíneas do gênero Urochloa em diferentes profundidades de semeadura. $O$ experimento foi conduzido, na Casa de Vegetação e Laboratório de Análise de Sementes da UNOESTE, localizados em Presidente Prudente (SP), em 2013. Utilizando sementes comerciais, oriundas de um mesmo lote, revestidas e não revestidas com grafite, polímero, fungicidas e inseticidas, dos cultivares La Libertad (MG4), Xaraés, Marandú e Piatã (Urochloa brizantha), Basilisk (U. decumbens), Kennedy (Ruziziensis) (U. ruziziensis), sendo todas do mesmo lote, obtidas em Presidente Prudente (SP). As curvas de embebição, emergência, produção de massa seca de raiz, parte aérea e massa seca total em diferentes profundidades (zero; 1,75; 2,5; 5,0 e 7,5 cm) foram determinadas. Observou-se que a absorção de água, protrusão da raiz, emergência e índice de velocidade de emergência nas sementes revestidas é mais lenta do que nas sementes não revestidas. Independente do revestimento de sementes, os cultivares Piatã e Ruziziensis tiveram bom desempenho na profundidade de semeadura entre 2,5 e 3,5 cm; MG4 até 4,5 cm; Basilisk entre 4,0 e 5,0 cm; Marandu e Xaraés são as mais tolerantes ao aprofundamento de semeadura na faixa entre 4,0 e $6,0 \mathrm{~cm}$.

Palavras-chave: embebição; emergência; gramíneas; Urochloa; velocidade de emergência.

\section{IMBEBITION AND SOWING DEPTH OF COATING AND UNCOATING OF FORAGES SEEDS}

\begin{abstract}
The aim of this work was to evaluate the seed coating effects during imbibition, emergency and early growth of six forages of Urochloa genus in different sowing depths. The experiment was conducted in the greenhouses and in the Seed Analysis Laboratory at UNOESTE, Presidente Prudente (SP) during 2013. Seeds from the same batch of the cultivars La Libertad (MG4), Xaraés, Marandú and Piatã (Urochloa brizantha), Basilisk (U. decumbens) and Kennedy (Ruziziensis) (U. ruziziensis) were submitted or not to coating with graphite, polymer, fungicides and insecticide were obtained in Presidente Prudente. The imbibition curves; emergency; root, shoot and total dry mass production in different depth (zero; 1.75; 2.5; 5.0 e $7.5 \mathrm{~cm}$ ) were determined. The coated seed water absorption, root protrusion, emergency and emergency velocity index was slower than no coated seed. Regardless of the seed coat, the Piatã and Ruziziensis cultivars perform well in seeding depth between 2.5 and $3.5 \mathrm{~cm}$; MG4 up to $4.5 \mathrm{~cm}$; Basilisk between 4.0 and $5.0 \mathrm{~cm}$; Marandu and Xaraés are more tolerant sowing depth in the range between 4.0 and $6.0 \mathrm{~cm}$.

Keywords: embebition; emergency; grassplot; Urochloa; emergency speed.
\end{abstract}

\section{INTRODUÇÃO}

O mercado de sementes de forrageiras foi se tornando mais exigente e o produtor passou a tratar a pastagem com cultura de grande importância econômica, e segundo Teodoro et al. (2011) foi a partir de 2000 que as empresas foram estimuladas a melhorar a qualidade das sementes comercializadas em virtude da crescente demanda do mercado consumidor e da certificação de sementes.

$\mathrm{Na}$ busca por melhorias do padrão de germinação das sementes, as empresas passaram 
a adotar o revestimento de sementes, técnica esta que foi inicialmente utilizada em sementes de hortaliças.

Atualmente as sementes de forrageiras são comercializadas sem revestimento e revestidas (incrustadas). A incrustação em forrageiras consiste na escarificação mecânica e tratamento com macro, micronutrientes, fungicidas, e pode aumentar em até cinco vezes o seu tamanho sem alterar o seu formato; melhora a pureza física e facilita a semeadura devido ao seu aumento de tamanho (BRITES et al., 2011), com isso tem proporcionado uniformidade na semeadura.

Essa tecnologia proporciona melhorias na semeadura, porém o revestimento retarda a embebição e consequentemente a germinação de Urochloa brizantha cV. BRS Piatã (SANTOS et al., 2011); reduz a velocidade de germinação e emergência de plântulas de Urochloa brizantha cv. Marandu (SANTOS et al., 2010); Braquiária híbrida (obtida através do cruzamento das espécies Urochloa brizantha, Urochloa decumbens e Urochloa ruziziensis) cv. Mulato II (FERREIRA et al., 2015) e retarda a absorção de água e protrusão da raiz primária em sementes Urochloa brizantha cv. Xaraés e Urochloa ruziziensis cv. Kennedy (DERRÉ et al., 2013).

O processo de semeadura, deve ser observado com cuidado, pois a profundidade de deposição da semente é um dos fatores que mais afeta a germinação, além da temperatura, teor de água e tipo de solo (SILVA et al., 2008), por isso a semente deve ser depositada a uma profundidade que não comprometa sua emergência.

Estudos em diferentes profundidades de semeadura possibilitam determinar a faixa ideal para cada espécie e/ou variedade, pois em alguns casos é desejável uma disparidade na emergência das espécies em consórcio, que pode ser conseguido com semeadura mais profunda de uma das espécies; em outros casos, profundidades de semeadura que possibilitem emergência rápida e uniforme são as ideais.

Como o revestimento de sementes interfere na velocidade de germinação e consequentemente na emergência, é importante estudar o comportamento dessas sementes em diferente profundidades de semeadura. Não há relatos de estudos com revestimento de sementes associada a profundidade de semeadura. Foloni et al. (2009a) avaliando U. brizantha cV. MG-5 observaram maior emergência com semeadura, em vaso, a $2,5 \mathrm{~cm}$ de profundidade. Foloni et al. (2009b), verificaram que para a $U$. brizantha cv. Marandú a melhor profundidade de semeadura, em vaso, foi a $2,5 \mathrm{~cm}$ no solo, e ineficiente abaixo de $5 \mathrm{~cm}$.

Como o revestimento de sementes interfere na velocidade de germinação das sementes é importante estudar a melhor resposta quanto à profundidade de semeadura, sendo assim, o objetivo foi avaliar os efeitos do revestimento de sementes durante a embebição, emergência e crescimento inicial de gramíneas do gênero Urochloa em diferentes profundidades de semeadura.

\section{MATERIAL E MÉTODOS}

O experimento foi conduzido em Casa de Vegetação e no Laboratório de Análise de Sementes da Universidade do Oeste Paulista, localizados em Presidente Prudente (SP), em 2013. Foram utilizadas sementes comerciais não revestidas (nuas) e revestidas das variedades Urochloa brizantha cv. La Libertad (MG4), Urochloa brizantha cv. Xaraés, Urochloa brizantha cv. Marandú, Urochloa brizantha cv. Piatã, Urochloa decumbens cv. Basilisk e Urochloa Ruziziensis cv. Kennedy (Ruziziensis). As sementes não revestidas e revestidas de cada variedade eram provenientes do mesmo lote, ou seja, antes de passar pelo tratamento de revestimento foi retirada uma porção de sementes, de cada lote e mantidas sem o revestimento. $O$ revestimento foi realizado em escala comercial contendo polímero, grafite, fungicidas e inseticidas (Advanced $^{\mathrm{TM}}$ ).

A massa de 1000 sementes foi obtida a partir de oito repetições de 100 sementes para cada variedade estudada, nas sementes não revestidas e revestidas, as quais foram pesadas em balança de precisão, conforme as Regras para Análise de Sementes (BRASIL, 2009), expressando-se os valores médios com e sem correção da umidade para $13 \%$. Com os valores corrigidos foi calculada a razão de revestimento dividindo-se a massa das sementes revestidas pela massa das não revestidas.

Sabendo que existe diferença na velocidade de germinação das sementes não revestida em relação as sementes revestidas, foi realizado um estudo com diferentes espécies e cultivar para verificar quando ocorre protrusão de raiz para os diferentes materiais estudados.

Para cada cultivar, tanto para as sementes não revestidas como para as sementes revestidas, foi determinada a curva de embebição 
de água, utilizando três repetições de 100 sementes por tipo de sementes, com pesagens realizadas em 18 períodos de embebição $(0,1,2$, $3,4,5,6,7,8,9,10,12,24,48,72,96,120$ e 144 horas), com as sementes dispostas em caixas plásticas transparentes para germinação (tipo gerbox), sobre duas folhas de papel de germinação umedecidas com água destilada na quantidade equivalente a 2,5 vezes a massa do papel, mantidas em temperatura de 25 o. . Transcorrido cada período, determinou-se a massa úmida das sementes e estas foram levadas para estufa a 105 ㅇ por 24 horas, e pesadas novamente para obtenção da massa seca. Os dados obtidos foram utilizados para calcular o teor de água das sementes em cada período (BRASIL, 2009).

Para os dados de embebição utilizou-se o delineamento inteiramente casualizado e a comparação entre sementes não revestidas e revestidas em cada período foram realizadas pelo teste $F(p \leq 0,05)$.

Além da curva de embebição, as sementes não revestidas e revestidas das diferentes variedades foram avaliadas quanto à emergência e índice de velocidade de emergência em diferentes profundidades de semeadura (zero; 1,$75 ; 2,5 ; 5,0$ e $7,5 \mathrm{~cm}$ ). O substrato utilizado nos vasos consistiu de uma mistura de solo e substrato comercial, na proporção de 1:1. A análise química dessa mistura apresentou os seguintes resultados: 5,0 de $\mathrm{pH}\left(\mathrm{CaCl}_{2}\right) ; 3,7 \mathrm{~g} \mathrm{dm}^{-3}$ de matéria orgânica; $171,5 \mathrm{mg} \mathrm{dm}^{-3}$ de fósforo (método de extração: Resina); $35,2 \mathrm{mg} \mathrm{dm}^{-3}$ enxofre; $0 \mathrm{mmol}_{\mathrm{c}} \mathrm{dm}^{-3}$ alumínio; $43,1 \mathrm{mmol}_{\mathrm{c}} \mathrm{dm}^{-3}$ hidrogênio + alumínio; $6,5 \mathrm{mmol}_{c} \mathrm{dm}^{-3}$ de potássio; $33,8 \mathrm{mmol}_{c} \mathrm{dm}^{-3}$ de cálcio; 17,4 $\mathrm{mmol}_{\mathrm{c}} \mathrm{dm}^{-3}$ de magnésio; $57,6 \mathrm{mmol}_{c} \mathrm{dm}^{-3}$ de soma de bases; $100,7 \mathrm{mmol}_{\mathrm{c}} \mathrm{dm}^{-3}$ de capacidade de troca de cátions; $0 \%$ de saturação por alumínio; 57,2 \% saturação por bases.

Os vasos foram confeccionados com tubos de PVC de $150 \mathrm{~mm}$ de diâmetro compostos com anéis de $2,5 \mathrm{~cm}$ para obtenção das diferentes profundidades de semeadura; a base de cada anel era de $15 \mathrm{~cm}$, e sobrepondo a base colocaram-se os demais anéis, os quais foram unidos com fita adesiva plástica. Todos os vasos continham o mesmo volume de solo, e em cada vaso semearam-se 100 sementes e cada tratamento era composto por quatro vasos, mantidos em casa de vegetação coberta com plástico e equipada com sistema automatizado de ventilação, umidificação e irrigação.
As avaliações foram realizadas diariamente considerando-se plântulas emergidas aquelas com altura superior a $1 \mathrm{~cm}$, e aos 28 dias após a semeadura, quando não houve mais incremento diário, calculou-se a emergência final, em porcentagem, seguindo a metodologia descrita por Nakagawa (1999). O índice de velocidade de emergência (IVE) foi calculado de acordo com a metodologia proposta por Maguire (1962).

Ao final do teste de emergência, as plantas foram removidas dos vasos e lavadas para retirada do substrato aderido as raízes em peneiras de malha $2 \mathrm{~mm}$, posteriormente procedeu-se a secagem das plantas em estufa (60 ${ }^{\circ} \mathrm{C}$ por $48 \mathrm{~h}$ ) para determinação da massa de matéria seca de raiz (MSR), massa de matéria seca da parte aérea (MSA) e massa de matéria seca de raiz e parte aérea (MSRA).

O delineamento experimental utilizado, para cada variedade, foi inteiramente casualizado, em esquema fatorial 2 (presença ou ausência revestimento) $\times 5$ (profundidade de semeadura: zero; 1,$75 ; 2,5 ; 5,0$ e $7,5 \mathrm{~cm}$ ), com quatro repetições. Quando indicado resultado significativo pela análise de variância $(p \leq 0,05)$, a presença ou ausência de revestimento foi comparada pelo próprio teste $F$, enquanto que o fator profundidade foi avaliado por regressão polinomial $(p \leq 0,05)$, optando-se pela equação significativa com maior coeficiente de determinação. Para a análise dos dados foi utilizado o programa estatístico SISVAR (FERREIRA, 2011).

\section{RESULTADOS E DISCUSSÃO}

$O$ revestimento das sementes promoveu o aumento da sua massa, praticamente dobrando-a em todos os cultivares estudados com exceção do cultivar Basilisk cuja razão de revestimento foi de 1,7 (Tabela 1). Em relação ao teor de água das sementes, é possível observar que as sementes não revestidas apresentam teor de água superior às sementes revestidas, independente do cultivar (Tabela 1). Isso é explicado pelo fato do revestimento aumentar a massa de sementes e ser constituído de material que não retém água, como salientam Câmara e Seraphin (2002).

O teor de água das sementes é uma informação importante para tomada de decisão relacionada ao manuseio do produto dentro de uma unidade de beneficiamento. Uma semente revestida com teor de água de $4,5 \%$, considerado adequado para o armazenamento, pode estar com seu núcleo, ou seja, a semente, com 
umidade bem mais elevada, ou seja, podendo chegar a um valor superior em $80 \%$, o que representa uma umidade de aproximadamente $8,1 \%$, conforme demonstrado através dos dados de razão de revestimento apresentados na Tabela 1.

Isso leva a pressupor que, a operação de secagem, durante as operações de revestimento, deve ser conduzida até que o núcleo (semente) esteja apresentando teor de água adequado às operações posteriores de embalagem e armazenamento. Portanto, a determinação do teor de água da semente revestida pode levar a conclusões equivocadas caso não seja considerado as características de baixa retenção de água dos materiais usados para revestimento da semente e o aumento de sua massa.

Tabela 1. Valores médios obtidos para $\mathrm{U}=$ teor de água (\%), mms = massa de mil sementes (g) e RR = razão de revestimento de sementes não revestidas e revestidas de Urochloa brizantha cv La Libertad (MG4), Urochloa brizantha cv Xaraés, Urochloa brizantha cv Marandú, Urochloa brizantha cv Piatã, Urochloa decumbens cv Basilisk, Urochloa ruziziensis cv Kennedy (Ruziziensis).

\begin{tabular}{|c|c|c|c|c|c|c|c|}
\hline \multirow[t]{2}{*}{ CULTIVARES } & \multicolumn{2}{|c|}{ U (\%) } & \multicolumn{2}{|c|}{ MMS (g) } & \multicolumn{2}{|c|}{ MMS $(g)^{1}$} & \multirow[t]{2}{*}{$\mathrm{RR}$} \\
\hline & NR & $R$ & NR & $R$ & NR & $R$ & \\
\hline Urochloa brizantha cv La Libertad (MG4) & 8,5 & 4,7 & 7,29 & 14,38 & 7,67 & 15,75 & 2,1 \\
\hline Urochloa brizantha cv Xaraés & 7,9 & 4,6 & 10,68 & 20,74 & 11,31 & 22,74 & 2,0 \\
\hline Urochloa brizantha cv Marandú & 6,3 & 4,4 & 8,71 & 17,53 & 9,38 & 19,26 & 2,1 \\
\hline Urochloa brizantha cv Piatã & 8,1 & 4,5 & 10,50 & 21,67 & 11,09 & 23,79 & 2,1 \\
\hline Urochloa decumbens cv Basilisk & 7,9 & 4,4 & 6,16 & 10,25 & 6,52 & 11,26 & 1,7 \\
\hline $\begin{array}{l}\text { Urochloa ruziziensis } \quad \mathrm{cv} \\
\text { (Ruziziensis) }\end{array}$ & 7,9 & 4,3 & 6,48 & 13,39 & 6,86 & 14,73 & 2,1 \\
\hline
\end{tabular}

$\mathrm{U}=$ teor de água das sementes, MMS=massa de mil sementes, $\mathrm{NR}=$ semente não revestida, $\mathrm{R}=$ semente revestida. ${ }^{1}=$ massa de mil sementes com umidade corrigida para 13\%, RR=razão de revestimento com valores corrigidos para $13 \%$ (MMS R. MMS NR ${ }^{-1}$ ).

Na Figura 1, 2 e 3 observa-se a evolução da embebição das sementes, para todos os cultivares, caracterizando o padrão trifásico de absorção de água. 0 modelo trifásico estabelecido em Bewley et al. (2012), considera que a Fase I de embebição ocorre na primeira hora, possibilitando crescente aumento na taxa inicial de embebição. Essa fase caracteriza-se por um processo físico, independente da atividade metabólica da semente, devido à acentuada diferença entre os potenciais hídricos da semente e do substrato. Após o período de 1 hora verificase uma estabilização no ganho de massa, demonstrando uma lenta absorção de água, comumente encontrada na fase II. Nesta fase, ocorre uma intensa atividade respiratória e acentuados processos metabólicos importantes para o desenvolvimento e crescimento embrionário, estimulando a germinação, sendo representada pela protrusão radicular, dando início a Fase III onde há o aumento no ganho de água, devido à necessidade de água pelas novas células em processo de formação da plântula (MARCOS FILHO, 2005).
Desta maneira, a Fase III para as sementes não revestidas foi iniciada após as 72 horas de embebição para os cultivares Xaraés, Marandu, Basilisk e Ruziziensis (Figuras 1A, 2A, e 3 A e B) e 96 horas para os cultivares MG4 e Piatã (Figura $1 \mathrm{~A}$ e $2 \mathrm{~B}$ ), quando ocorreu a protrusão radicular. Enquanto que para as sementes revestidas a Fase III foi iniciada após 72 horas de embebição para os cultivares Basilisk e Ruziziensis (Figura 3 A e B), 96 horas para os cultivares MG4, Piatã (Figura 1A e $2 B$ ) e 120 horas e 144 horas para os cultivares Marandu e Xaraés, respectivamente, (Figura 2A e 1B). Após emissão da raiz primária há uma retomada na absorção de água conforme demostrado nas Figuras 1 , 2 e 3 .

O tratamento com sementes revestidas reduziu velocidade de embebição (Figura 1, 2 e 3 ) corroborando os dados observados por Custódio et al. (2011) em sementes de Urochloa brizantha cv Marandu escarificadas e peliculizadas. Santos et al. (2011) ressaltam que o revestimento das sementes de $U$. brizantha cv. BRS Piatã, com polímero, gesso e fertilizantes, interfere na velocidade de germinação das sementes. Embora o revestimento das sementes utilizadas por esses 
autores seja diferente do revestimento das sementes utilizada nesse experimento esses dados demostram que a presença dessa camada de revestimento interfere na velocidade de absorção de água pelas sementes e consequentemente reflete na velocidade de germinação. Resultado semelhante também foi verificado por Pereira et al. (2011) em sementes de $U$. decumbens $c v$. Basilisk revestidas com microcelulose + areia + cola - PVA (20\%).
Verifica-se também que as sementes não revestidas apresentaram maior teor de água quando comparadas com as sementes revestidas, indicando que o tratamento com polímero reduziu a velocidade de embebição, o que pode estar relacionado a interferências nas trocas gasosas, dificultado a respiração e absorção de água pelas sementes, pois o grafite não absorve água conforme constatado por Yen et al. (2004).
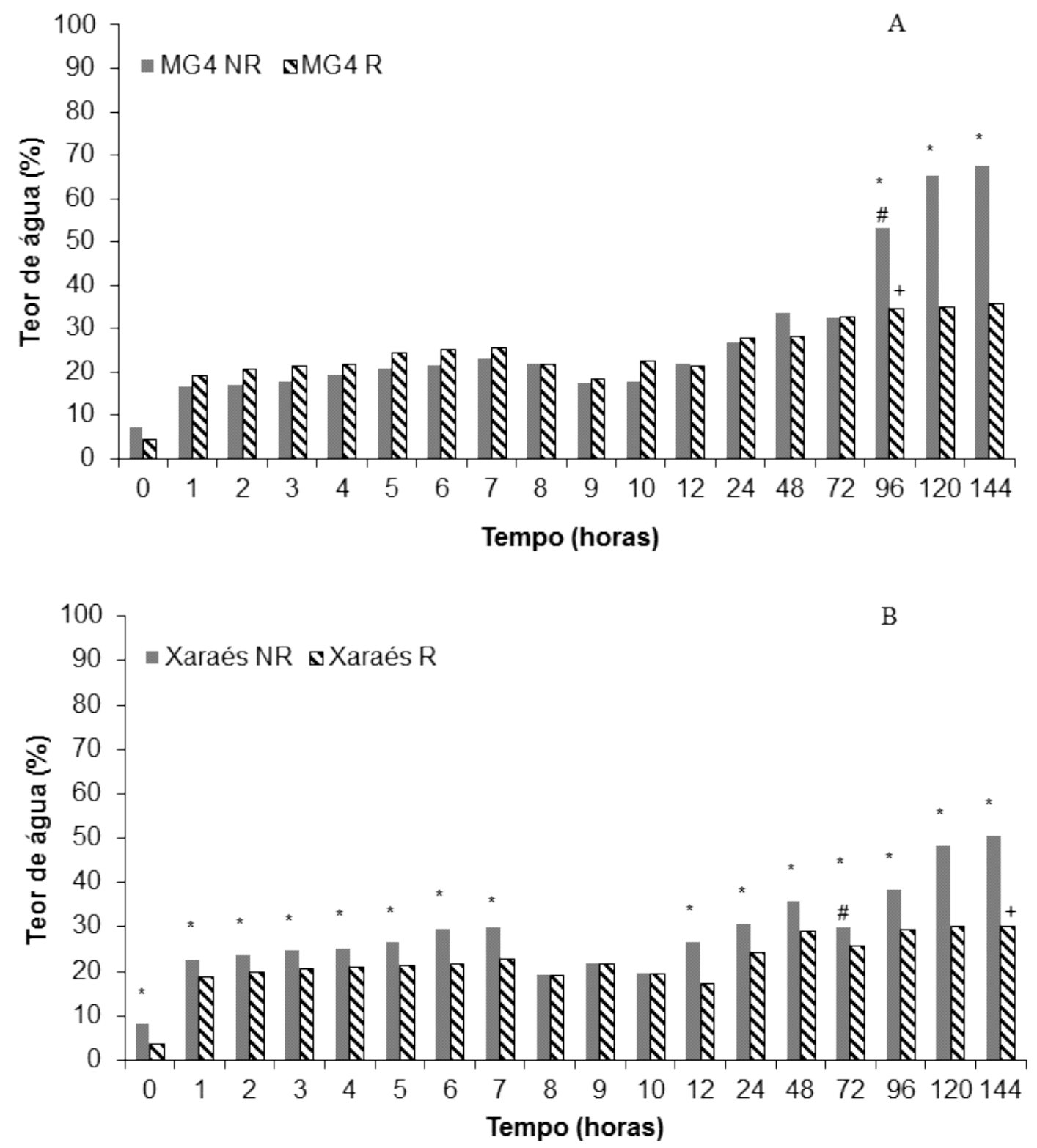

Figura 1. Teor de água em diferentes períodos de embebição em sementes não revestidas (NR) e revestidas (R) de: A - Urochloa brizantha cv La Libertad (MG4) e B - Urochloa brizantha cv Xaraés, Presidente Prudente/SP, 2013. *Diferença significativa a 5\% de probabilidade pelo Teste F entre a semente NR e R. \# Início visível da germinação (\% de protrusão de raiz primária) sementes NR de 9,0 e 1,7\% e + sementes $\mathrm{R}$ de 4,7 e 0,3\%, respectivamente para A e B. 

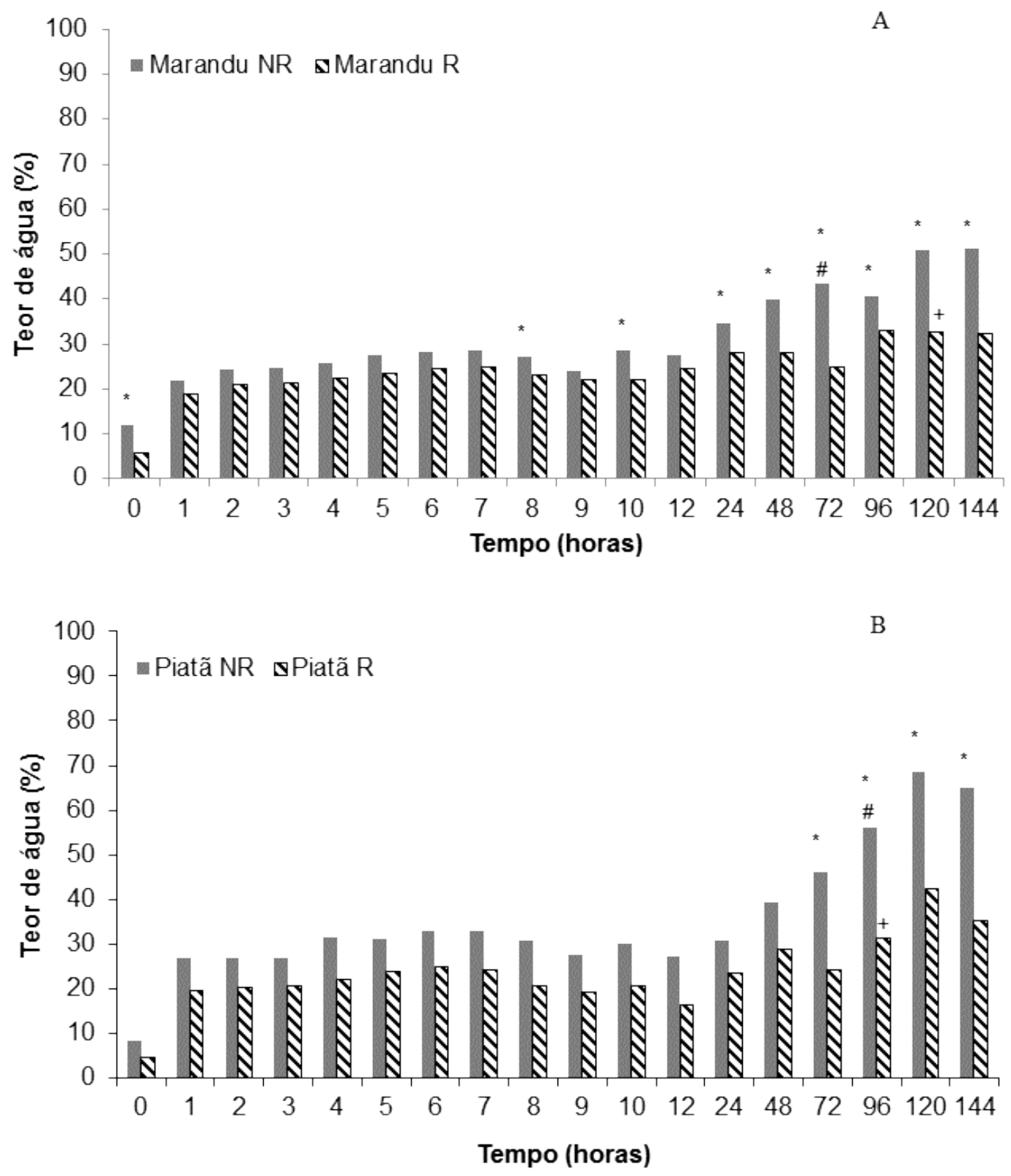

Figura 2. Teor de água em diferentes períodos de embebição em sementes não revestidas (NR) e revestidas (R) de: A - Urochloa brizantha cv Marandú e B - Urochloa brizantha cv Piatã. Presidente Prudente/SP, 2013. *Diferença significativa a $5 \%$ de probabilidade pelo Teste $\mathrm{F}$ entre a semente NR e R. \# Início visível da germinação (\% de protrusão de raiz primária) sementes NR de 9,7 e 2,3\% e + sementes $\mathrm{R}$ de 0,3 e 0,3\%, respectivamente para $\mathrm{A}$ e $\mathrm{B}$. 

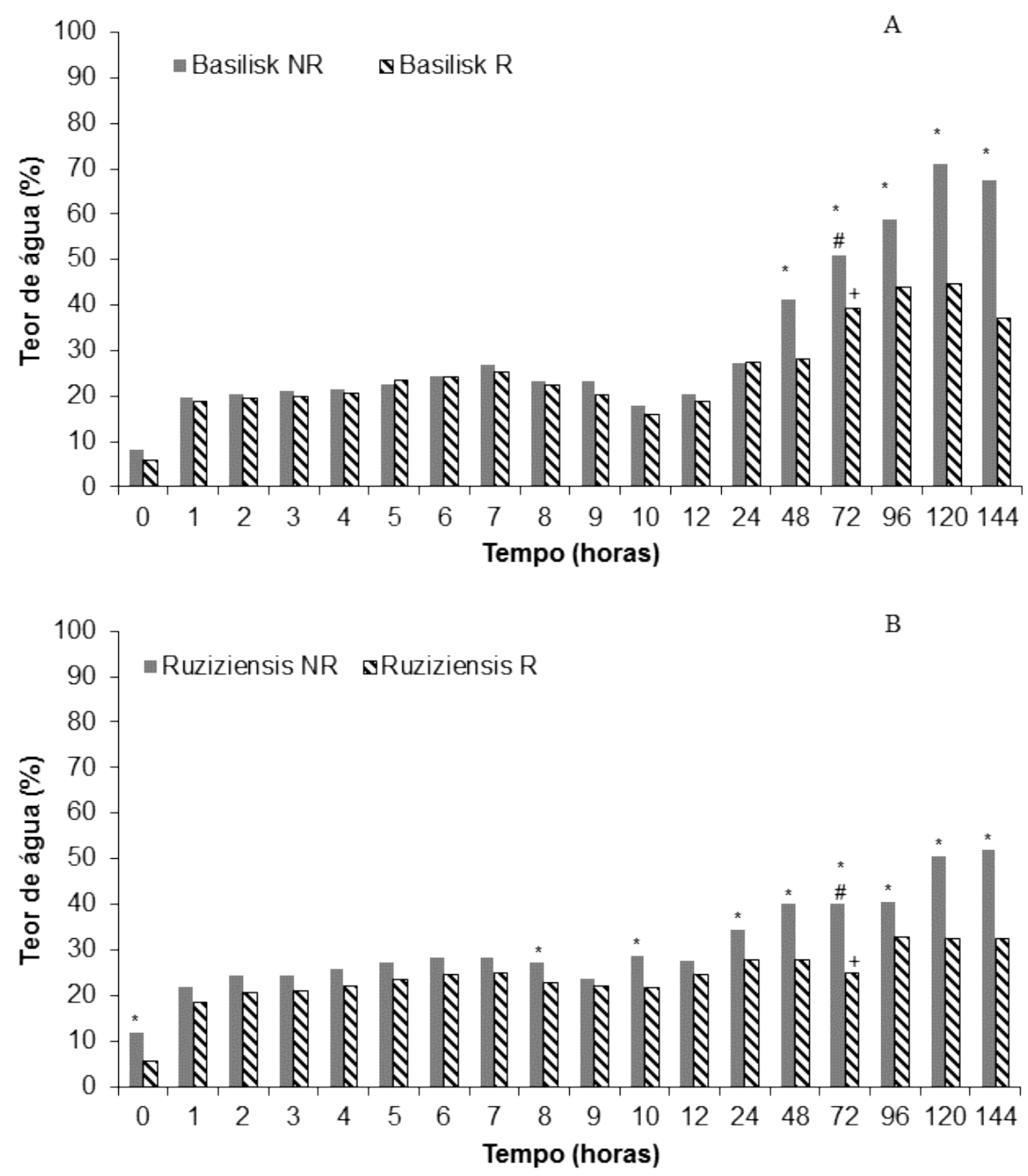

Figura 3. Teor de água em diferentes períodos de embebição em sementes não revestidas (NR) e revestidas (R) de: A - Urochloa decumbens cv Basilisk e B - Urochloa ruziziensis cv Kennedy (Ruziziensis). Presidente Prudente/SP, 2013. * Diferença significativa a $5 \%$ de probabilidade pelo Teste $\mathrm{F}$ entre a semente NR e R. \# Início visível da germinação (\% de protrusão de raiz primária) sementes NR de 3,3 e 3,0\% e + sementes R de 3,6 e $2,7 \%$, respectivamente para A e B.

Em relação ao revestimento da semente e a profundidade de semeadura não houve interação entre esses fatores para nenhuma variável avaliada (Tabelas 2, 3 e 4). As sementes não revestidas dos cultivares MG4, Xaraés e Marandu apresentaram maior porcentagem de emergência de plântulas do que as sementes revestidas, enquanto que para os cultivares Piatã, Basilisk e Ruziziensis a ausência ou a presença do revestimento não interferiu significativamente na emergência de plântulas (Tabela 2).
O índice de velocidade de emergência foi maior para as sementes não revestidas para MG4, Xaraés, Marandu e Piatã, demonstrando que a velocidade de emergência das plântulas desses cultivares é influenciada pelo revestimento das sementes, mas para Basilisk e Ruziziensis não houve efeito do revestimento das sementes na velocidade de emergência de plântulas (Tabela 2) o que pode estar relacionado à menor massa das sementes de ambos os cultivares (Tabela 1). Com menor massa é necessário proporcionalmente menor quantidade 
de água para atingir o suficiente para germinação.

Santos et al. (2010) estudando quatorze tipos de revestimento associados ou não a fungicida e inseticida também verificaram que o revestimento de sementes promove a redução da velocidade de germinação e emergência de plântulas de Urochloa brizantha cv. Marandu, independentemente do tipo de revestimento. Ferreira et al. (2015) também verificaram que o revestimento em sementes de Braquiária híbrida cv. Mulato II reduz a germinação, emergência e índice de velocidade de emergência. Derré et al. (2013) avaliaram a capacidade de embebição de sementes revestidas e não revestidas de Urochloa brizantha cv Xaraés e Urochloa ruziziensis cv Kennedy e observaram que o revestimento por incrustação promoveu uma menor absorção de água e isso pode restringir a emergência e a velocidade de emergência de plântulas.

Sabendo que o revestimento interfere na absorção de água e na velocidade de germinação é importante estudar a profundidade de semeadura mais adequada para esse tipo de semente. Trabalhando com diferentes profundidades de semeadura verificou-se que a profundidade não interferiu na emergência de plântulas e no índice de velocidade de emergência dos cultivares MG4 e Xaraés e na emergência de Marandu (Tabela 2) avaliada aos 28 dias após a semeadura. Entretanto, o cultivar Marandu apresentou efeito da profundidade de semeadura para o índice de velocidade de emergência, com maior índice na profundidade de 1,98 cm (Tabela 2).
Em relação ao cultivar Piatã, observou-se que a porcentagem de emergência de plântulas e o índice de velocidade de emergência se ajustaram às funções quadráticas, com os valores máximos sendo alcançados, respectivamente, com a estimativa de 2,63 cm e 2,49 cm de profundidade de semeadura (Tabela 2).

Para o cultivar Basilisk houve efeito da profundidade de semeadura, sendo que a resposta à profundidade se ajustou a um modelo quadrático, tanto para a emergência quanto para o índice de velocidade de emergência, com aumento na emergência e no índice até a profundidade estimada de $3,97 \mathrm{~cm}$ e 4,15 cm, respectivamente (Tabela 2 ).

No entanto, para o cultivar Ruziziensis (Tabela 2), o efeito foi quadrático para emergência com a máxima porcentagem de emergência alcançada na profundidade estimada de 2,43 cm e linear decrescente para IVE, ou seja, à medida que houve aumento da profundidade $o$ IVE apresentou decréscimo, e consequentemente o estabelecimento da plântula foi mais lento.

Contudo, a semeadura em maiores profundidades pode ser utilizada em situações de solos arenosos e com possibilidade de ocorrência de veranicos, porém é preciso cuidado, pois semeaduras muito profundas afetam negativamente a emergência das plântulas. Esse recurso, no entanto, não deveria ser aplicado para materiais mais sensíveis ao aprofundamento como Piatã e Ruziziensis que apresentaram redução na porcentagem de emergência de plântulas. 
Tabela 2. Médias para porcentagem de emergência de plântulas (E) e índice de velocidade de emergência (IVE), Urochloa brizantha cv La Libertad (MG4), Urochloa brizantha cv Xaraés, Urochloa brizantha cv Marandu, Urochloa brizantha cv Piatã, Urochloa decumbens cv. Basilisk, Urochloa ruziziensis cv Kennedy

\begin{tabular}{|c|c|c|c|c|c|c|c|c|c|c|c|c|}
\hline \multirow[t]{2}{*}{ Tratamento } & \multicolumn{2}{|c|}{ MG4 } & \multicolumn{2}{|c|}{ Xaraés } & \multicolumn{2}{|c|}{ Marandu } & \multicolumn{2}{|c|}{ Piatã } & \multicolumn{2}{|c|}{ Basilisk } & \multicolumn{2}{|c|}{ Ruziziensis } \\
\hline & $\mathrm{E}$ & IVE & $E$ & IVE & $E$ & IVE & $\mathrm{E}$ & IVE & $E$ & IVE & $E$ & IVE \\
\hline \multicolumn{13}{|l|}{ Semente (A) } \\
\hline Não revestida & $54,50 \mathrm{a}$ & 31,03 a & 59,60 a & 29,68 a & $78,30 \mathrm{a}$ & $35,53 a$ & 52,40 & $31,24 \mathrm{a}$ & 42,95 & 28,02 & 40,85 & 28,71 \\
\hline Revestida & $40,60 \mathrm{~b}$ & $28,85 b$ & $45,95 b$ & $28,55 b$ & $61,60 \mathrm{~b}$ & $32,17 b$ & 51,75 & $30,24 \mathrm{~b}$ & 48,00 & 27,60 & 45,85 & 29,71 \\
\hline \multicolumn{13}{|c|}{ Profundidade $(\mathrm{cm})(\mathrm{B})$} \\
\hline 0,00 & 40,87 & 29,23 & 49,87 & 28,89 & 70,25 & 34,00 & 53,87 & 30,95 & 35,37 & 26,66 & 46,12 & 30,91 \\
\hline 1,75 & 49,25 & 30,04 & 54,87 & 29,29 & 73,50 & 35,62 & 60,87 & 32,90 & 51,12 & 28,47 & 48,50 & 29,69 \\
\hline 2,50 & 53,75 & 30,52 & 54,25 & 29,14 & 69,87 & 34,07 & 66,50 & 32,85 & 49,12 & 28,27 & 46,74 & 29,03 \\
\hline 5,00 & 47,75 & 29,93 & 56,50 & 29,49 & 70,37 & 33,61 & 56,37 & 30,78 & 51,50 & 28,09 & 47,75 & 29,77 \\
\hline 7,50 & 46,12 & 30,00 & 48,37 & 28,75 & 65,75 & 31,93 & 22,75 & 26,21 & 40,25 & 27,57 & 27,62 & 26,65 \\
\hline Regressão & ns & ns & ns & ns & ns & $Q^{1}$ & $\mathrm{Q}^{2}$ & $Q^{3}$ & $Q^{4}$ & $Q^{5}$ & $Q^{6}$ & $\mathrm{~L}^{7}$ \\
\hline & \multicolumn{12}{|c|}{ Valores de $\mathrm{F}$} \\
\hline A & $14,78^{* *}$ & $20,41 * *$ & $25,87^{* *}$ & $18,97 * *$ & $53,43 * *$ & $55,41^{* *}$ & $0,03^{\text {ns }}$ & $4,69 *$ & $2,15^{\mathrm{ns}}$ & $1,57^{\text {ns }}$ & $2,16^{\mathrm{ns}}$ & $2,63^{\text {ns }}$ \\
\hline B & $1,35^{\mathrm{ns}}$ & $0,73^{\mathrm{ns}}$ & $1,34^{\mathrm{ns}}$ & $1,07^{\text {ns }}$ & $1,17^{\mathrm{ns}}$ & $6,82^{* *}$ & $15,65^{* *}$ & $27,79 * *$ & $3,56^{*}$ & $3,87 *$ & $5,39 * *$ & $5,25^{* *}$ \\
\hline$A \times B$ & $0,76^{\mathrm{ns}}$ & $0,80^{\mathrm{ns}}$ & $0,85^{\mathrm{ns}}$ & $1,20^{\mathrm{ns}}$ & $0,53^{\mathrm{ns}}$ & $1,62^{\mathrm{ns}}$ & $2,46^{\mathrm{ns}}$ & $1,17^{\mathrm{ns}}$ & $0,47^{\mathrm{ns}}$ & $0,51^{\mathrm{ns}}$ & $0,86^{\mathrm{ns}}$ & $0,23^{\text {ns }}$ \\
\hline
\end{tabular}

Médias seguidas de letras distintas, na coluna, para o fator tipo de semente, diferem estatisticamente entre si, pelo teste $\mathrm{F}$ a $5 \%$ de probabilidade. Para interação e para regressão: $n$ ns, ** e * são: não-significativo e significativo a $1 \%$ e a $5 \%$ de probabilidade pelo teste $F$, respectivamente. ${ }^{1}: y=34,297+0,373 x-0,094 x^{2}, R^{2}=80 \%{ }^{*} ;{ }^{2}: y=52,843+9,348 x-1,778 x^{2}, R^{2}=$ $99 \%^{* *} ;{ }^{3}: y=31,119+1,322 x-0,265 x^{2}, R^{2}=99 \%^{* *} ;{ }^{4}: y=36,320+8,55 x-1,076 x^{2}, R^{2}=93 \%^{*} ;{ }^{5}: y=26,892+0,797 x-0,096 x^{2}, R^{2}=79 \% * * ;{ }^{*}: y=44,800+3,957 x-0,812 x^{2}, R^{2}=92 \%^{*} ;{ }^{7}: 30,768-$ $0,456 x, R^{2}: 74 \% * *$.Para o cultivar MG4 não foi observado efeito entre os tratamentos para massa seca de raiz (MSR), no entanto constatou-se maior massa seca de parte aérea (MSA) e de raiz e parte aérea (MSRA) nas plantas originadas de sementes sem revestimento (Tabela 3). Este fato pode ser explicado pela emergência das sementes não revestidas ocorrerem mais rápido do que as sementes revestidas (Tabela 2). Enquanto que para a profundidade, o ajuste dos dados foi quadrático, com maior massa observada na profundidade estimada de $4,67 \mathrm{~cm}$ e $4,47 \mathrm{~cm}$, para MSA e MSRA, respectivamente (Tabela 3). 
Para o cultivar Xaraés (Tabela 3) não houve efeito do revestimento de sementes para MSR, de MSA e de MSRA, e a profundidade influenciou as três variáveis, sendo que para MSR o ajuste foi quadrático com maior massa estimada na profundidade de $5,24 \mathrm{~cm}$, enquanto que a MSA aumentou linearmente com a profundidade de semeadura. No entanto, para a MSRA o ajuste foi quadrático obtendo a maior massa na profundidade estimada de $6,15 \mathrm{~cm}$.

Para o cultivar Marandu observou-se que não houve diferenças para a variável MSR, MSA e MSRA, com relação ao revestimento de semente (Tabela 3). A produção de MSA e MSRA, quando relacionada com a profundidade apresentaram efeito linear, com acréscimo de produção de massa seca mediante $o$ aumento da profundidade de semeadura.
Os cultivares Xaraés e Marandu apresentaram maior massa seca de parte aérea mediante $\mathrm{o}$ aumento da profundidade de semeadura e esse fato pode estar relacionado a uma reação do cultivar em buscar a luz, translocando mais massa seca para a parte aérea em detrimento da massa seca de raiz, pois de acordo com Lambers et al. (2008) algumas espécies de plantas podem investir mais em folhas de modo a aumentar a captação de luz em ambientes sombreados.

Pacheco et al. (2010) trabalhando com Urochloa brizantha cv. Marandu, Urochloa decumbens, Urochloa ruziziensis e Pannicum maximum cv. Tanzânia, verificaram que a redução de na massa seca de parte aérea é mais intensa a partir de $8 \mathrm{~cm}$ e para raiz a partir de 4 $\mathrm{cm}$ de profundidade.

Tabela 3. Médias para massa de matéria seca de raiz (MSR), massa de matéria seca de parte aérea (MSA) e massa de matéria seca de raiz e parte aérea (MSRA) em gramas, Urochloa brizantha cv. La Libertad (MG4), Urochloa brizantha cv Xaraés, Urochloa brizantha cv Marandu

\begin{tabular}{|c|c|c|c|c|c|c|c|c|c|}
\hline \multirow[t]{2}{*}{ Tratamentos } & \multicolumn{3}{|c|}{ MG4 } & \multicolumn{3}{|c|}{ Xaraés } & \multicolumn{3}{|c|}{ Marandu } \\
\hline & MSR & MSA & MSRA & MSR & MSA & MSRA & MSR & MSA & MSRA \\
\hline \multicolumn{10}{|l|}{ Semente (A) } \\
\hline Não revestida & 5,62 & $13,57 \mathrm{a}$ & 19,19 a & 4,52 & 9,42 & 13,94 & 5,58 & 12,29 & 17,87 \\
\hline Revestida & 5,84 & $10,82 \mathrm{~b}$ & $16,66 \mathrm{~b}$ & 4,35 & 9,12 & 13,48 & 6,08 & 11,47 & 17,56 \\
\hline \multicolumn{10}{|c|}{ Profundidade $(\mathrm{cm})(\mathrm{B})$} \\
\hline 0,00 & 5,91 & 9,82 & 15,74 & 3,42 & 8,17 & 11,60 & 5,12 & 9,97 & 15,09 \\
\hline 1,75 & 5,51 & 12,38 & 17,89 & 3,84 & 8,57 & 12,40 & 6,11 & 11,54 & 17,64 \\
\hline 2,50 & 5,49 & 12,95 & 18,43 & 4,85 & 9,43 & 14,28 & 5,76 & 11,94 & 17,70 \\
\hline 5,00 & 6,60 & 13,47 & 20,07 & 5,35 & 10,16 & 15,51 & 6,22 & 12,73 & 18,95 \\
\hline 7,50 & 5,14 & 12,35 & 17,49 & 4,73 & 10,01 & 14,74 & 5,94 & 13,23 & 19,17 \\
\hline \multirow[t]{2}{*}{ Regressão } & ns & $\mathrm{Q}^{1}$ & $Q^{2}$ & $\mathrm{Q}^{3}$ & $\mathrm{~L}^{4}$ & $Q^{5}$ & ns & $\mathrm{L}^{6}$ & $\mathrm{~L}^{7}$ \\
\hline & \multicolumn{9}{|c|}{ Valores de F } \\
\hline$A$ & $0,10^{\text {ns }}$ & $27,63 * *$ & $11,79 * *$ & $0,17^{\text {ns }}$ & $0,66^{\text {ns }}$ & $0,59^{\text {ns }}$ & $1,88^{\text {ns }}$ & $3,50^{\text {ns }}$ & $0,189^{\text {ns }}$ \\
\hline B & $0,58^{\text {ns }}$ & $5,78 * *$ & $3,62 *$ & $3,07 *$ & $4,61^{* *}$ & $6,03 * *$ & $1,13^{\text {ns }}$ & $6,70^{* *}$ & $3,97^{*}$ \\
\hline$A \times B$ & $1,02^{\mathrm{ns}}$ & $0,78^{\mathrm{ns}}$ & $2,01^{\mathrm{ns}}$ & $1,21^{\mathrm{ns}}$ & $1,01^{\mathrm{ns}}$ & $1,06^{\mathrm{ns}}$ & $0,95^{\mathrm{ns}}$ & $1,10^{\text {ns }}$ & $0,61^{\mathrm{ns}}$ \\
\hline
\end{tabular}

Médias seguidas de letras distintas, na coluna, para o fator tipo de semente, diferem estatisticamente entre si, pelo teste $\mathrm{F}$ a $5 \%$ de probabilidade. Para interação e para regressão: $\mathrm{ns},{ }^{*} \mathrm{e}^{*}$ são: não significativo e significativo a $1 \%$ e a $5 \%$ de probabilidade pelo teste $F$, respectivamente. ${ }^{1}: y=9,925+1,615 x-0,173 x^{2}, R^{2}=99 \%^{* *} ;{ }^{2}: y=15,51+1,834 x-0,205 x^{2}$, $R^{2}=94 \%^{* *} ;{ }^{3}: y=3,25+0,734-0,070 x^{2}, R^{2}=86 \%^{*} ;{ }^{4}: y=8,37-0,267 x, R^{2}=80 \% * ; \quad: y=11,27+1,355 x-0,11 x^{2}, R^{2}: 89 \% * ;$ ${ }^{6}: y=10,057+0,404 x, R^{2}=89 \% * *, 7: y=16,05+0,49 x, R^{2}=80 \% * *$.

Para o cultivar Piatã (Tabela 4), verificou-se que a MSR, MSA e MSRA das plantas originadas de sementes não revestidas foram superiores às massas das plantas provenientes de sementes revestidas, assim como observado para MG4 para MSA e MSRA, o que pode ser explicado pelo fato de que as sementes não revestidas germinaram e emergiram mais rápido, garantindo um crescimento inicial maior, já que as plantas foram medidas na mesma época e as sementes revestidas tiveram uma germinação mais lenta o que reflete no crescimento inicial. Em relação à profundidade de semeadura para MSR, MSA e MSRA, a resposta dessas variáveis se ajustou a um modelo quadrático, sendo as maiores massas obtidas na profundidade estimada, respectivamente, de $3,35 \mathrm{~cm}, 3,14 \mathrm{~cm}$ e $3,22 \mathrm{~cm}$.

O cultivar Basilisk não houve efeito do tratamento de sementes (não revestidas e revestidas) e profundidade de semeadura na 
MSR, enquanto que para a MSA e MSRA, o efeito observado foi apenas para profundidade de semeadura com resposta quadrática (Tabela 4). A maior massa calculada foi encontrada na profundidade estimada de 5,05 $\mathrm{cm}$ para MSA e de $4,71 \mathrm{~cm}$ para MSRA.

Para o cultivar Ruziziensis não foi verificada diferença entre as sementes não revestidas e revestidas para MSR, MSA e MSRA, porém para profundidade houve efeito em todas as variáveis com ajuste quadrático, sendo as maiores massas estimadas nas profundidades de 3,19, 3,60 e de $3,41 \mathrm{~cm}$, respectivamente (Tabela 4).

Teodoro et al. (2011) verificaram que sementes sem revestimento, revestidas e tratadas com inseticida não influenciaram na produção de biomassa da Urochloa brizantha cv MG5, nas frações folha, colmo e raiz, comportando-se de maneira semelhante até 60 dias após a emergência, independentemente de ser revestida ou não, assim como observado neste trabalho para MG4, Marandu e Basilisk.

De maneira geral, a maioria dos cultivares estudados nesse trabalho tiveram ganho de massa até as profundidades entre 3,0 e 3,4 cm, com exceção de Basilisk e Xaraés que se mostram mais tolerantes a profundidades de semeadura entre 4,0 e $5,0 \mathrm{~cm}$ e 5,0 e $6,0 \mathrm{~cm}$, respectivamente (Tabela 2 e 3 ).

Entretanto os cultivares que foram mais rápidos na emergência de plântulas têm potencial para produzir maior massa seca de plantas, pois inicia o processo de fotossíntese primeiro que os materiais mais lentos e com isso deixa de depender apenas das reservas da semente, resultando em plantas com maior massa de matéria seca.

Tabela 4. Médias para massa de matéria seca de raiz (MSR), massa de matéria seca de parte aérea (MSA) e massa de matéria seca de raiz e parte aérea (MSRA) em gramas, Urochloa brizantha cv Piatã, Urochloa decumbens cv. Basilisk, Urochloa ruziziensis cv. Ruziziensis

\begin{tabular}{|c|c|c|c|c|c|c|c|c|c|}
\hline \multirow[t]{2}{*}{ Tratamentos } & \multicolumn{3}{|c|}{ Piatã } & \multicolumn{3}{|c|}{ Basilisk } & \multicolumn{3}{|c|}{ Ruziziensis } \\
\hline & MSR & MSA & MSRA & MSR & MSA & MSRA & MSR & MSA & MSRA \\
\hline \multicolumn{10}{|l|}{ Semente $(A)$} \\
\hline Não revestida & 4,65 a & $11,84 a$ & 16,49 a & 4,79 & 8,47 & 13,26 & 4,55 & 8,34 & 12,89 \\
\hline Revestida & $3,51 b$ & $8,63 \mathrm{~b}$ & $12,14 \mathrm{~b}$ & 4,21 & 8,95 & 13,16 & 4,77 & 9,21 & 13,98 \\
\hline \multicolumn{10}{|c|}{ Profundidade $(\mathrm{cm})(\mathrm{B})$} \\
\hline 0,00 & 3,16 & 9,05 & 12,21 & 3,19 & 5,95 & 9,15 & 4,12 & 7,94 & 12,05 \\
\hline 1,75 & 5,13 & 12,72 & 17,85 & 4,94 & 8,75 & 13,69 & 5,83 & 9,15 & 14,98 \\
\hline 2,50 & 5,17 & 11,66 & 16,83 & 5,09 & 9,06 & 14,14 & 5,12 & 9,42 & 14,54 \\
\hline 5,00 & 4,69 & 11,49 & 16,18 & 5,09 & 10,40 & 15,49 & 5,47 & 10,40 & 15,87 \\
\hline 7,50 & 2,26 & 6,23 & 8,49 & 4,20 & 9,37 & 13,57 & 2,76 & 6,97 & 9,73 \\
\hline \multirow[t]{2}{*}{ Regressão } & $\mathrm{Q}^{1}$ & $\mathrm{Q}^{2}$ & $\mathrm{Q}^{3}$ & ns & $Q^{4}$ & $Q^{5}$ & $Q^{6}$ & $Q^{7}$ & $Q^{8}$ \\
\hline & \multicolumn{9}{|c|}{ Valores de $\mathrm{F}$} \\
\hline$A$ & $10,03 * *$ & $19,14^{* *}$ & $18,68^{* *}$ & $1,54^{\mathrm{ns}}$ & $0,49^{\text {ns }}$ & $0,008^{\text {ns }}$ & $0,28^{\text {ns }}$ & $1,60^{\text {ns }}$ & $1,17^{\text {ns }}$ \\
\hline B & $10,59 * *$ & $10,09 * *$ & $11,97^{* *}$ & $2,51^{\mathrm{ns}}$ & $4,70 * *$ & $4,23 * *$ & $7,16^{* *}$ & $3,01^{*}$ & $4,96 * *$ \\
\hline$A \times B$ & $1,31^{\text {ns }}$ & $1,77^{\mathrm{ns}}$ & $1,72^{\mathrm{ns}}$ & $1,94^{\mathrm{ns}}$ & $0,79^{\text {ns }}$ & $1,33^{\mathrm{ns}}$ & $0,17^{\mathrm{ns}}$ & $0,96^{\mathrm{ns}}$ & $0,46^{\mathrm{ns}}$ \\
\hline
\end{tabular}

Médias seguidas de letras distintas, na coluna, para o fator tipo de semente, diferem estatisticamente entre si, pelo teste $\mathrm{F}$ a $5 \%$ de probabilidade. Para interação e para regressão: ns, ** e * são: não-significativo e significativo a $1 \%$ e a $5 \%$ de probabilidade pelo teste $F$, respectivamente. ${ }^{1}: y=3,270+1,236 x-0,184 x^{2}, R^{2}=98 \% * * ;{ }^{2}: y=9,220+2,113-0,335 x^{2}$, $R^{2}=95 \% * ;{ }^{3}: y=12,490+3,349 x-0,519 x^{2}, R^{2}=97 \% * * ;{ }^{4}: y=6,008+1,730 x-0,171 x^{2}, R^{2}=99 \% *{ }^{5}: y=9,33+2,716 x-0,288 x^{2}$, $R^{2}=98 \% * * ;{ }^{6}: y=4,133+1,016 x-0,159 x^{2}, R^{2}=91 \% * * ;{ }^{7}: y=7,640+1,361-0,189 x^{2}, R^{2}=87 \% * * ;{ }^{8}: y=11,772+2,377 x-0,348 x^{2}$, $\mathrm{R}^{2}: 92 \% * *$.

\section{CONCLUSÕES}

A absorção de água, protrusão da raiz, emergência e índice de velocidade de emergência nas sementes revestidas é mais lenta do que nas sementes não revestidas.

Independente do revestimento de sementes, os cultivares Piatã e Ruziziensis tem bom desempenho na profundidade de semeadura entre 2,5 e $3,5 \mathrm{~cm}$; MG4 até $4,5 \mathrm{~cm}$; Basilisk entre 4,0 e 5,0 cm; Marandu e Xaraés são as mais tolerantes ao aprofundamento de semeadura na faixa entre 4,0 e 6,0 cm.

\section{REFERÊNCIAS}

BEWLEY, J.D.; BRADFORD, K.J.; HILHORST, H.W.M.; NONOGAKI, H. Seeds: physiology of 
development, germination and dormancy. New York: Springer Science \& Business Media, 3ed., 2012. $392 \mathrm{p}$.

BRASIL. Ministério da Agricultura, Pecuária e Abastecimento. Regras para análise de sementes. Brasília: Ministério da Agricultura, 2009. $395 \mathrm{p}$.

BRITES, F.H.R.; SILVA JUNIOR, C.A.; TORRES, F.E. Germinação de semente comum, escarificada e revestida de diferentes espécies forrageiras tropicais. Bioscience Journal, v.27, n.4, p.629634, 2011. http://www.seer.ufu.br/index.php/biosciencejou rnal/article/view/11267/7754

CÂMARA, H.H.L.L; SERAPHIN, S.E. Germinação de sementes de Urochloa brizantha cv Marandu sob diferentes períodos de armazenamento e tratamento hormonal. Pesquisa Agropecuária Tropical, v.32, n.1, p.21-28, 2002. http://www.revistas.ufg.br/index.php/pat/article /view/2436

CUSTÓDIO, C.C.; AMBIEL, A.C.; RODRIGUES, D.Z.; AGOSTINI, E.A.T.; FACTUR, V.D.; PAVANELLI, L.E. Peliculização de sementes não revestidas e escarificadas de Urochloa brizantha (HOCHST. Ex a. Rich.) Stapf. Pesquisa Agropecuária Tropical, v.41, n.3, p.314-321, 2011. http://www.revistas.ufg.br/index.php/pat/article /view/9146.

https://doi.org/10.5216/pat.v41i3.9146

DERRÉ, L.O.; CUSTÓDIO, C.C.; AGOSTINI, E.A.T.; GUERRA, W.E.X. Obtenção das curvas de embebição de sementes revestidas e não revestidas de Urochloa brizantha e Urochloa ruziziensis. Colloquium Agrariae, v.9, n.2, p.103111 , 2013. http://dx.doi.org/10.5747/ca.2013.v09.n2.a094 FERREIRA, D. F. Sisvar: um sistema computacional de análise estatística. Ciência e Agrotecnologia, v.35, n.6, p.1039-1042, 2011. http://dx.doi.org/10.1590/S1413-

70542011000600001

FERREIRA, V.F.; FERREIRA, T.F.; CARVALHO, R.A.; MAVAIEIE, D.P.R.; PEREIRA, D.S.; OLIVEIRA, J.A. Qualidade fisiológica de sementes revestidas de braquiária híbrida cv. Mulato II. Revista Agro@mbiente, v.9, n.2, p.161-166, 2015. http://revista.ufrr.br/index.php/agroambiente/ar ticle/view/2471/1579

FOLONI, S.S.; CUSTÓDIO, C.C.; CALDEIRA, F.J.; CALVO, C.L. Emergência de plântulas de Brachiaria brizanthai influenciada por escarificação das sementes, uso de adubo e profundidade de semeadura. Revista Científica, v.37, n.2, p.89-97,

2009b.

http://dx.doi.org/10.15361/1984-

$5529.2009 v 37 n 2 \mathrm{p} 89+-+97$

FOLONI, S.S.; CUSTÓDIO, C.C.; POMPEI, F.P.; VIVAN, M.R. Instalação de espécie forrageira em razão da profundidade no solo e contato com fertilizante formulado NPK. Pesquisa Agropecuária Tropical, v.39, n.1, p.7-12, 2009a. http://www.revistas.ufg.br/index.php/pat/article /view/3313/4462

LAMBERS, H.; CHAPIN, F.S.; PONS, T.L. Plant physiological ecology. New York: Springer Science \& Business Media, 2008. 605p. https://doi.org/10.1007/978-0-387-78341-3

MAGUIRE, J.D. Speeds of germination-aid selection and evaluation or seedling emergence and vigor. Crop Science, v.2, n.2, p.176-177, 1962.

https://doi.org/10.2135/cropsci1962.0011183X0 00200020033x

MARCOS FILHO, J. Fisiologia de sementes de plantas cultivadas. Piracicaba: Fealq, 2005. 495p. NAKAGAWA, J. Testes de vigor baseados no desempenho das plântulas. In: Krzyzanowskl, F.C.; Vieira, R.D.; França, N.J.B. Vigor de sementes: conceitos e testes. Londrina: Abrates, 1999, 24p.

PACHECO, L.P.; PIRES, F.R.; MONTEIRO, F.P.; PROCÓPIO, S. O.; ASSIS, R. L. DE.; PETTER, F. A. Profundidade de semeadura e crescimento inicial de espécies forrageiras utilizadas para cobertura do solo. Ciência e Agrotecnologia, v.34, n.5, p.1211-1218, 2010. http://dx.doi.org/10.1590/S1413-

70542010000500019

PEREIRA, C.E.; OLIVEIRA, J.A.; ROSA, M.C.M.; KIKUTI, A.L.P. Armazenamento de sementes de braquiária peletizadas e tratadas com fungicida e inseticida. Ciência Rural, v.41, n.12, p.2060-2065, 2011. http://revistas.bvsvet.org.br/crural/article/view/21109.

https://doi.org/10.1590/S0103-

84782011001200004

SANTOS, F.C.; OLIVEIRA, J.O.; PINHO, E.V.R. GUIMARÃES, R.M.; VIEIRA, A.R. Tratamento químico, revestimento e armazenamento de sementes de Brachiaria brizantha cv Marandu. Revista Brasileira de Sementes, v.32, n.3, p.6978, 2010. http://dx.doi.org/10.1590/S010131222010000300008

SANTOS, L.D.C.; BENETT, C.G.S.; SILVA, K.S.; SILVA, L.V. Germinação de diferentes tipos de sementes de Brachiaria brizantha cv. BRS Piatã. Bioscience Journal, v.27, n.3, p.420-426, 2011. 
http://www.seer.ufu.br/index.php/biosciencejou rnal/article/view/8073/7557

SILVA, R.P.; CORÁ, J.E.; FURLANI, C.E.A.; LOPES, A. Efeito da profundidade de semeadura e de rodas compactadoras submetidas a cargas verticais na temperatura e no teor de água do solo durante a germinação de sementes de milho. Ciência e Agrotecnologia, v.32, n.3, p.929-937, 2008. http://www.scielo.br/readcube/epdf.php?doi=10 .1590/S1413-70542008000300034\&pid=S141370542008000300034\&pdf_path=cagro/v32n3/a3 $4 \mathrm{v} 32 \mathrm{n} 3 . \mathrm{pdf}$

TEODORO, A.N.; OLIVEIRA, M.V.M.; LONGO, M.L; RUFINO, J.; MIRANDA, F.; FERREIRA, D. Influência do revestimento de sementes e tratamento com inseticida no desenvolvimento e características nutricionais da Brachiaria brizantha CV MG-5 Vitória. Revista Agrarian, v.4, n.13, p.213-221, 2011.

http://www.periodicos.ufgd.edu.br/index.php/ag rarian/article/view/860/762

YEN, B.K.; SCHWICKERT, B..; TONEY, M.F. Origin of low-friction behavior in graphite investigated by surface $x$-ray diffraction. Applied physics letters, v.84, n.23, p.4702-4704, 2004. http://dx.doi.org/10.1063/1.1760597

Recebido para publicação em 26/09/2016

Revisado em 03/02/2017

Aceito em 17/02/2017 